\section{Review}

Correspondence

Christian Hannig

christian.hannig@uniklinik-

freiburg.de

\title{
Visualization of adherent micro-organisms using different techniques
}

\author{
Christian Hannig, ${ }^{1}$ Marie Follo, ${ }^{2}$ Elmar Hellwig ${ }^{1}$ and Ali Al-Ahmad ${ }^{1}$ \\ ${ }^{1}$ Department of Operative Dentistry and Periodontology, University of Freiburg, Hugstetter Str. 55, \\ D-79106 Freiburg, Germany \\ ${ }^{2}$ Department of Hematology and Oncology, Core Facility, Albert-Ludwig University, Freiburg, \\ Germany
}

\begin{abstract}
The visualization and quantification of adherent bacteria is still one of the most relevant topics in microbiology. Besides electron microscopic techniques such as transmission electron microscopy, scanning electron microscopy and environmental scanning electron microscopy, modern fluorescence microscopic approaches based on fluorogenic dyes offer detailed insight into bacterial biofilms. The aim of the present review was to provide an overview of the advantages and disadvantages of different methods for visualization of adherent bacteria with a special focus on the experiences gained in dental research.
\end{abstract}

\section{Oral biofilm - an example of adherent micro-organisms}

In 1675, Leeuwenhoek was the first to detect microorganisms using a microscope in water and in saliva. Only a few years later, he was already investigating bacteria in adherent oral biofilms. Since then, oral biofilm formation has been investigated thoroughly using different approaches. In particular, the influence of different surfaces on the process of bioadhesion can be easily explored (Hannig \& Hannig, 2009). Much experience on the visualization of in situ or in vivo formed biofilms has been gained in the area of dental research, and the methods which were adopted have proven to be of relevance to all other fields of microbiology (Nyvad \& Kilian, 1987; Hannig, 1999; Bergmans et al., 2005; Hannig et al., 2007b). The efficacy of antibacterial oral health-care products as well as bacterial colonization of the oral hard and soft tissues, such as enamel, dentin, the root canal or periodontal pockets, have been intensively investigated (Marsh, 1993; Marsh \& Bradshaw, 1995; Netuschil et al., 1995; Hannig, 1999; Marsh \& Martin, 1999; Bergmans et al., 2005; Hannig et al., 2007b, 2009). A special advantage of oral biofilm research is the opportunity to non-invasively monitor biofilm formation in humans using samples of different materials mounted on individual splints for bacterial adherence in situ (Hannig \& Hannig, 2009). The aim of the present short review is to give an insight into traditional and current methods for the visualization and quantification of adherent bacteria or biofilms, with a special focus on the experiences gained in dental research.

\section{Quantification by determination of c.f.u.}

The traditional method of determining the number of adherent micro-organisms is the measurement of viability by prior desorption through the use of ultrasonication or vigorous agitation and subsequent plating on different agar plates (Hannig et al., 2007b). Though this technique has the advantage of determining the number of active bacteria, there are some disadvantages to it which could lead to misleading conclusions. This technique is not only both labour- and time-intensive but it may very well select for certain species when studying multispecies biofilms from natural niches (Amann et al., 1995; Donlan \& Costerton, 2002). Furthermore, it is difficult to quantify semi-planktonic adherent bacteria or desorbed biofilms (Hannig et al., 2007b, 2009; Al-Ahmad et al., 2008a, b). In Figs 1 and 2, flocks of adherent salivary bacteria are shown. Quantification of such adherent bacterial agglomerates with fluorescent dyes or by electron microscopy can differ considerably from the c.f.u. numbers after ultrasonication (Hannig et al., 2007b; Al-Ahmad et al., 2009a). Only a very low percentage of bacteria in seawater, earth or sewage sludge are culturable. This illustrates the necessity of methods other than culture plates for the visualization, quantification and identification of bacteria (Amann et al., 1995).

\section{High-resolution microscopic techniques}

Though light microscopy as well as fluorescence microscopy allow the visualization of bacteria, higher-resolution techniques are required for detailed insight into the ultrastructure of the bacteria and the surrounding matrix. Several microscopic techniques with completely different physical background are available. All electron microscopic methods offer detailed insight into the ultrastructure of bacteria and their environment but quantification of the adherent micro-organisms is difficult. 

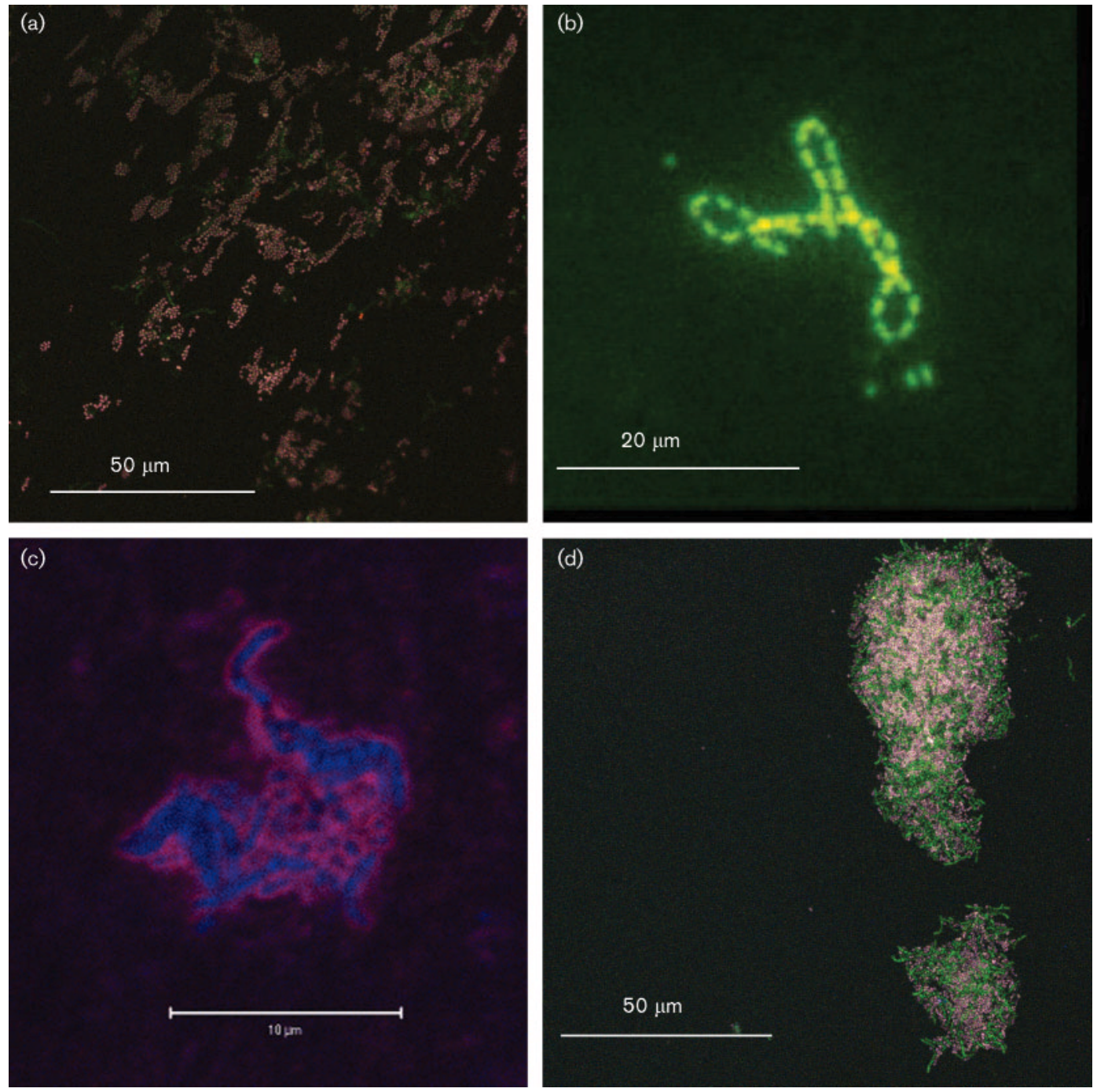

Fig. 1. Examples of visualization of adherent micro-organisms with fluorogenic dyes. (a) Adherent bacteria, streptococci (magenta) and other eubacteria (green). Biofilm formation on enamel in situ for $12 \mathrm{~h}$. Original magnification 1000-fold; CLSM. (b) Chains of eubacteria on an enamel sample after $60 \mathrm{~min}$ exposure in the oral cavity; FISH, FDA-filter. Original magnification 1000-fold. (c) Visualization of glucans (red) associated with bacteria (blue). Biofilm formation on enamel in situ for $8 \mathrm{~h}$. Bacteria were stained with DRAQ5 and glucans with concanavalin A-Alexa Fluor 594. Original magnification 1000-fold; CLSM. (d) Aggregate of bacteria, FISH, streptococci (magenta) and other eubacteria (green). Biofilm formation on enamel in situ for $12 \mathrm{~h}$. Original magnification 1000-fold; CLSM.

Scanning electron microscopy (SEM) allows visualization of surface structures with a three-dimensional appearance at very different resolutions (Fig. 2). However, due to the high vacuum required for evaluation of the samples and due to the fact that biological samples have non-conductive properties, fixation, dehydration and coating with a conductive material are necessary. Therefore, procedures are required which do not destroy the structure of the samples or cause artefacts (Bergmans et al., 2005). After fixation with aldehydes in phosphate or cacodylate buffer, the dehydration is carried out with a series of ascending concentrations of acetone or ethanol. In this way, the water is gradually replaced by the organic solvents. Afterwards, the samples have to be dried without destruction of the complex structures. This is achieved by critical point drying without formation of artefacts. Thereafter, the ethanol is replaced by a transitional fluid, usually consisting of carbon dioxide. Alternatively, the samples can be freeze-dried. Finally the specimens have to be coated with a conductive material, for example sputtered with gold (Bergmans et al., 2005; Vitkov et al., 2005). With SEM, evaluation of different bacterial species is not possible. In addition, the differentiation of cocci, rods and filaments according to the appearance of the bacteria is sometimes difficult (Gusberti et al., 1985). However, SEM is a valuable tool for investigation of conditioning films or 


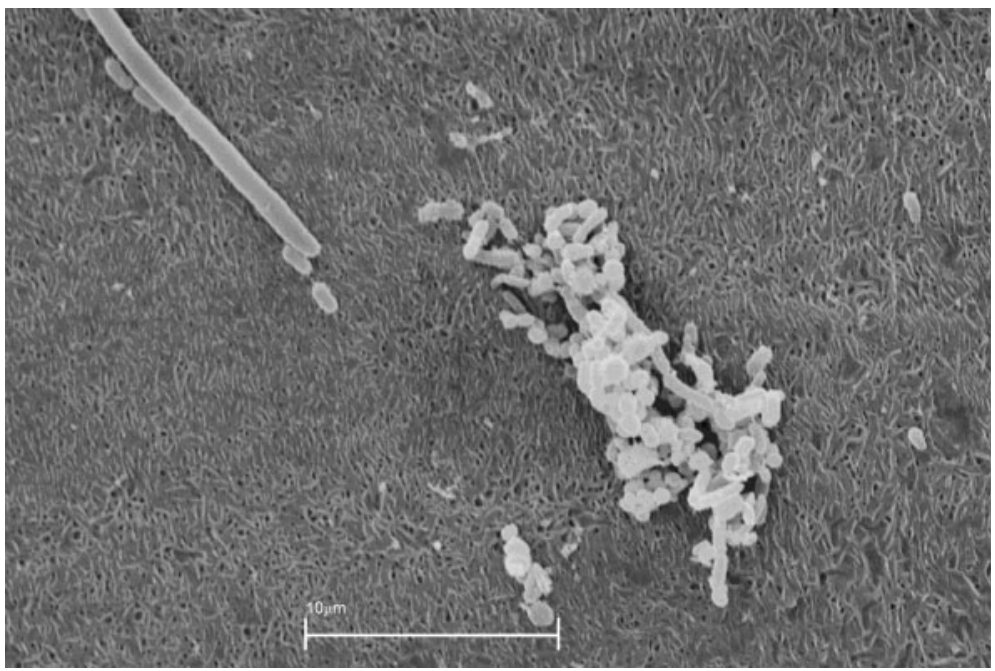

Fig. 2. Scanning electron micrographs of different poly(lactide-co-glycolic acid) 3Dscaffolds manufactured as bone replacement materials and colonized with salivary microorganisms. Magnification $\times 5000$.

proteinaceous layers such as the acquired dental pellicle (Hannig et al., 2007a, 2008). Therefore, SEM can be combined with gold-immunolabelling techniques for visualization and quantification of certain proteins (Hannig et al., 2007a, 2008).

The environmental scanning electron microscope (ESEM) allows investigation of bacteria without any dehydration, fixation or coating of bacteria in the natural state. This is a clear advantage. However, some species such as Fusobacterium nucleatum cannot be optimally visualized with this technique (Bergmans et al., 2005). Furthermore, three-dimensional visualization of the structures is sometimes limited.

The standard electron microscopic technique used for the evaluation of ultrathin sections is transmission electron microscopy (TEM). An important advantage of TEM is its high resolution of down to $0.1 \mathrm{~nm}$ (Bergmans et al., 2005). The indispensable fixation is typically carried out with glutaraldehyde or osmium tetroxide, which also stains lipids. A different option is cryo-fixation at $-135{ }^{\circ} \mathrm{C}$ to help avoid artefacts. However, the contrast is rather low. In addition, dehydration in a series of ascending concentrations of ethanol or acetone is necessary, as well as embedding in acrylic resin as a prerequisite for ultrathin sectioning. Additionally, staining with heavy elements such as lead citrate or uranyl acetate for the purpose of contrasting is often required. Summing up, it may be stated that TEM is an excellent method for the visualization of bacteria and the surrounding extracellular matrix as well as of the conditioning film or the dental pellicle but it is a very time-consuming and complex technique (Hannig \& Balz, 1999; Hannig et al., 2008). Nonetheless, due to its high resolution, TEM is still considered to be a gold standard in electron microscopy.

Cryo-electron microscopy of vitreous sections offers the opportunity of evaluating ultrathin sections of biological samples in a hydrated state. The essential principle of this technique is the formation of vitreous (non-crystalline) ice preserving the appearance of the sample in its soluble state. However, this approach also requires extensive preparation of the samples, as well as highly specialized equipment (Bouchet-Marquis \& Fakan, 2009).

Atomic force microscopy (AFM) can also reach a very a high resolution of less than $1 \mathrm{~nm}$, and has paved the way towards real nanomicrobiology as recently reviewed by Dufrene (2008). It has the great advantage in that vacuum conditions are not required. Membrane components and living cells can be evaluated directly in buffer or on solid substrates (Dufrene, 2008). Even real-time monitoring of structural changes due to the application of antibacterial agents as well as of cell-cell interactions is possible (Dufrene, 2008).

\section{Staining techniques}

Quantification of biofilm formation by different microorganisms can be carried out in a microtitre-plate test using different staining assays such as crystal violet or safranin and subsequent measurement of the absorbance of the biofilm using an ELISA in a microplate reader (Stepanovic et al., 2000; Kristich et al., 2004; Al-Ahmad et al., 2008a). This staining is primarily used for monitoring biofilm formation of micro-organisms in vitro.

Direct staining of adherent bacteria is possible using DAPI (4',6-diamidino-2-phenylindole) binding to the AT-rich regions of double-stranded DNA of vital and dead cells (Schwartz et al., 2003). This technique is also suitable for oral biofilms formed on enamel slabs, or for the visualization and calculation of the total bacterial count in comparison to the number of c.f.u. for bacteria which have adhered to biomaterials (Hannig et al., 2007b; AlAhmad et al., 2008b). However, no differentiation of bacterial species is possible with this simple technique. For this, one requires another fluorescence-based approach, fluorescence in situ hybridization (FISH) (Amann et al., 
1990; Paster et al., 1998). The FISH technique is based on oligonucleotide probes labelled with fluorescent dyes binding specifically to rRNA. A large number of intact ribosomes representing the biological activity of the tested cells is a prerequisite for this method, so that apparently only vital bacteria are stained (Amann et al., 1990, 1995; Amann, 1995; Hannig et al., 2007b). FISH has been successfully used in combination with confocal laser scanning microscopy (CLSM) and epifluorescence microscopy for the visualization of initial and mature oral biofilm formed in situ (Fig. 1) (Thurnheer et al., 2001; Al-Ahmad et al., 2007, 2009a, b; Dige et al., 2007; Hannig et al., 2007b).

Furthermore, fluorescent dyes are available for a number of proteins or molecules. As an example, the extracellular matrix can be visualized by using special glucan stainings such as concanavalin A (Fig. 1). In addition to the identification of species, the viability of the adherent bacteria is also of considerable interest. Several stages of viability are discussed and described in the literature: viable and culturable, viable but non-culturable, dormant, nonviable and pre-lytic, and avital dead bacteria (Decker, 2001). The exact differentiation of these stages is still one of the greatest challenges in modern microbiology (Mason et al., 1986; Lloyd \& Hayes, 1995; Decker, 2001). About $50 \%$ of oral bacteria are viable but not culturable, emphasizing the necessity of reliable viability assays (Aas et al., 2005). Typically, a combination of different dyes for vital and avital bacteria is used for this purpose. Apart from the stilldifficult definition of vital and avital bacteria, the problem of several live/dead staining techniques is the stability of the stainings. The interaction of different bacterial species with certain dyes differs distinctly, yielding different patterns of vitality (Decker, 2001). However, when investigating the efficacy of antibacterial rinses or reagents, it is of great relevance to visualize their effect on the viability of the adherent bacteria. Biofilms and adherent bacteria are often more resistant than free micro-organisms (Marsh, 1993). In this short overview, it is only possible to discuss some of the more common dyes out of the large number of reagents used. Many live/dead stains test the membrane integrity of the respective bacteria. Several vital bacterial stains are based on the formation of fluorescein as a result of intracellular esterase activity. It is a prerequisite that these substrates diffuse freely into the bacterial cells and yet remain within the interior of the cell after cleavage.

Fluorescein diacetate (FDA), one of the first dyes adopted, rapidly leaks from the cells and is rather unstable whereas carboxyfluorescein diacetate is better retained due to its negative charge (Leeder et al., 1989; Decker, 2001). Other dyes for the staining of vital cells, such as SYTO 17, which is able to penetrate intact membranes, are based on nucleic acid staining.

Many dyes for the staining of avital bacteria enter cells with damaged plasma membranes and bind to nucleic acids, yielding an enhancement in fluorescence of up to 1000-fold.

A typical stain for avital micro-organisms is ethidium bromide, but its toxicity led to the development of alternative reagents. Propidum iodide is superior to ethidium bromide and penetrates only damaged cells whereas ethidium bromide may also stain vital bacteria (Dangl et al., 1982; Decker, 2001). Furthermore, ethidium bromide is less reliable than propidium iodide as propidium iodide has a lower charge and therefore a higher affinity for DNA (Beletsky \& Umansky, 1990; Lopez-Amoros et al., 1995). Another option is modified ethidium homodimer-1 with its enhanced affinity for DNA, along with a low membrane permeability (Glazer et al., 1990). A further substrate, SYTOX, available as a green, orange or blue dye, is also based on the staining of nucleic acids and easily penetrates dead Gram-positive and Gram-negative cells with defective membranes, but is described as being completely excluded from vital bacteria (Roth et al., 1997).

FDA/ethidium bromide staining is poorly correlated with c.f.u. when investigating typical strains of oral streptococci (Decker, 2001), although this method has been described as being able to successfully differentiate vital and avital bacteria in oral biofilms (Netuschil et al., 1989). The combination of SYTO 9 with propidium iodide seems to be appropriate for oral streptococcal strains (Weiger et al., 1999; Decker, 2001).

These stains are also found within the BacLight Viability kit (Boulos et al., 1999). For vital cells, the small molecule SYTO 9 is used penetrating vital and avital cells, whereas the counterstain propidium iodide stains only dead cells (Peeters et al., 2008). This causes some difficulties in the evaluation of the data. Further studies are required to compare the newer live/dead staining techniques, especially for in vivo or in situ formed natural biofilms. Therefore, the stability of the staining as well as the correlation of the results with culture plate methods are important (Decker, 2001; Peeters et al., 2008).

In general, the compatibility of the different stains among themselves and in comparison to the culture plate methods should also be investigated with respect to the substrate that the bacteria adhere to (Hannig \& Hannig, 2009). Dental materials and dental hard tissues in particular may display heavy background fluorescence. Individual viability assays have to be adapted according to the different materials. A recent study compared different methods for quantification of biofilms formed in 96-well microtitre plates (Peeters et al., 2008). The authors tested the crystal violet assay, which stains the bacteria and the matrix of biofilm, the SYTO 9 assay, staining dead and viable biofilm bacteria, and DMMB (1,9-dimethyl methylene blue), which quantifies the biofilm matrix. In addition, several assays for the quantification of viable bacteria in the biofilm were compared: the XTT (tetrazolium salt) assay, which is based on the reduction of the XTT dye to a watersoluble formazan and quantifies viable bacteria; the resazurin (Alamar Blue) assay, which is based on the reduction of resazurin to pink resorufin; and the FDA assay. The authors concluded that although all assays can replace the determination of c.f.u., there are differences in 
the reproducibility of the different methods. Furthermore, it depends on the application and the species being studied for biofilm formation. In a study from our laboratory on oral biofilm formation, the compatibility of FISH, DAPI and live/dead (FDA/ethidium bromide) staining was shown for initial bacterial colonization on enamel in situ (Hannig et al., 2007b). However, the c.f.u. data differed significantly from fluorescence-based assays as a desorption step was necessary for determination of the c.f.u.

\section{Challenge of standardized evaluation of stained biofilms}

Though various excellent staining procedures are available, the three-dimensional, computer-based visualization, evaluation and quantification of biofilms is still a challenge. The structural organization of biofilms and the covering grade of substrata are important parameters which can describe the adaptation of micro-organisms to environmental influences (Møller et al., 1997; Nielsen et al., 2000; Al-Ahmad et al., 2008a). The determination of mean biofilm thickness and roughness, density, porosity, biovolume and covering grade is required in studying biofilm development and modulation, for example by variation of nutrition (Heydorn et al., 2000). Qualitative analysis and imaging of biofilm often leads to the question of whether the obtained data are representative of the observed biofilm, irrespective of the staining assay used. Korber et al. (1992, 1993) determined the minimum area that should be studied to describe biofilm formed by Pseudomonas aeruginosa. Heydorn et al. (2000) developed the computer program COMSTAT, which comprises 10 features for quantifying three-dimensional biofilm stacks (Heydorn et al., 2000; Chavez de Paz, 2009). Using this program, the authors analysed four variables describing biofilm structure of different Pseudomonas strains: mean thickness, roughness, substratum coverage and surface to volume ratio. This program is freely available from the COMSTAT homepage at http://www.im.dtu.dk/comstat and has been used by a large number of biofilm researchers (Schaber et al., 2007; Sauer et al., 2009).

Other software packages and biofilm processing methods have been developed for analysing colour image data to representatively quantify or determine the distribution and structure of microbial subpopulations (Yang et al., 2000, 2001; Xavier et al., 2001; Daims et al., 2006; Mueller et al., 2006). Recently, a novel image analysis software package, bioImage_L, was presented which allows in situ colour segmentation for two colour image stacks without prior transformation of micrographs into monochrome channels (Chavez de Paz, 2009). In our own studies, we successfully used a specific image analysis program (MetaMorph Molecular Devices) to quantify different bacterial targets in dental oral biofilms after detection with FISH in combination with CLSM (Al-Ahmad et al., 2007, 2009a,

Table 1. Survey of current methods for visualization and quantification of adherent micro-organisms with respect to their main advantages and limitations

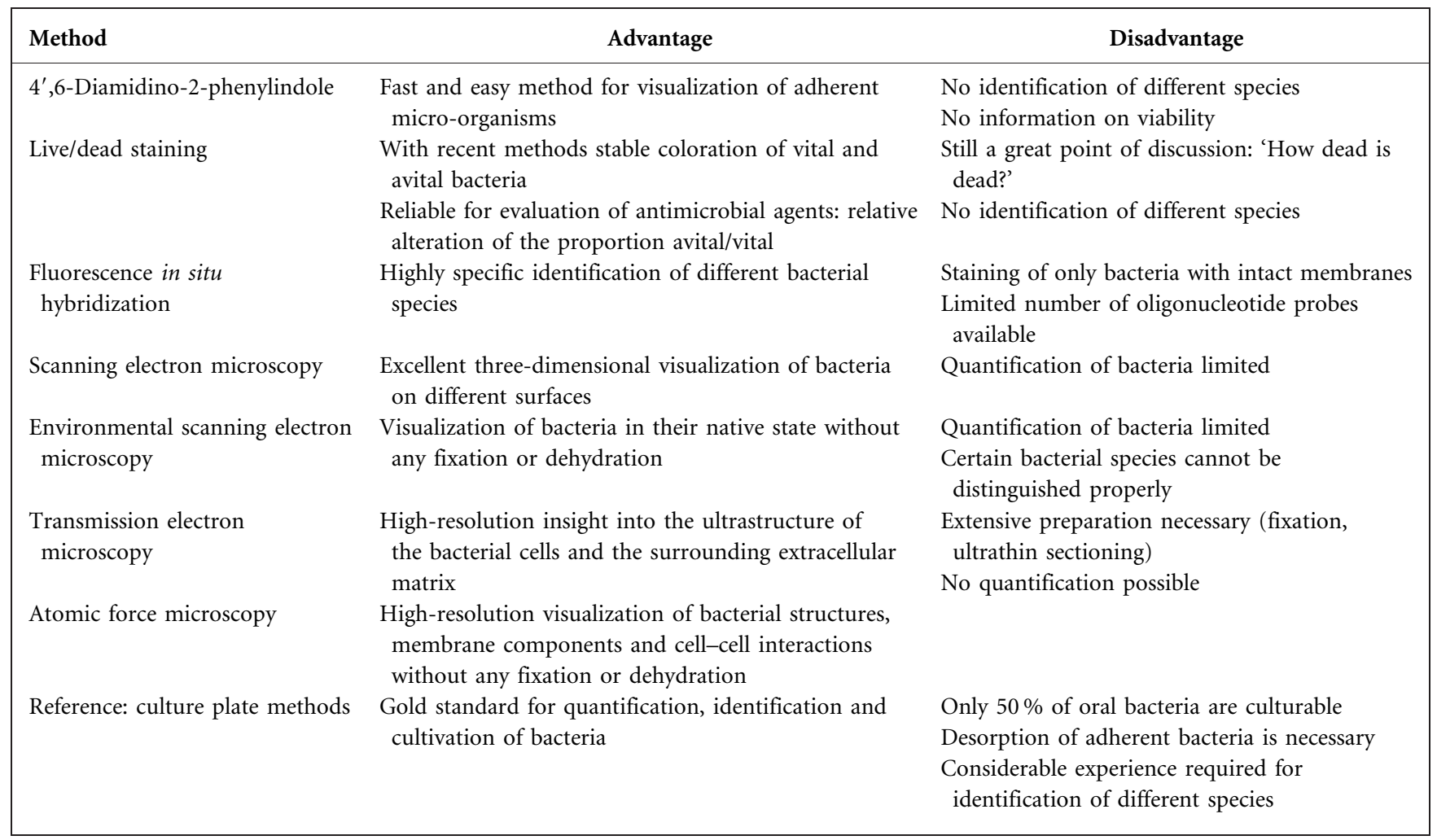


b). The covering grade of the substratum can also be analysed by this program, which is relevant in the monitoring of antibacterial effects on biofilm formation (Al-Ahmad et al., 2009a). It should be emphasized that automation of biofilm imaging should be correlated with a suitable image processing method.

\section{Concluding remarks}

Biofilm research is still a challenging field of interest and the techniques for quantification, visualization and characterization of micro-organisms have undergone rapid progress within the last 15 years. Central advantages and disadvantages are given in Table 1. However, some of these promising techniques, such as AFM or ESEM, require costly equipment while for others, such as TEM or SEM, extensive preparation of the samples is necessary (Hannig, 1999; Bergmans et al., 2005; Dufrene, 2008).

Moreover, many bacteria are not culturable, for example $50 \%$ of oral micro-organisms, even though they are vital or viable (Aas et al., 2005). This underlines the relevance of fluorescence stainings, which are relatively straightforward to perform compared with sample preparation for TEM (Hannig et al., 2007b). Furthermore, a well-documented difficulty of culture plate methods is that they select for particular species, leading to an overestimation of their levels. Due to the limited culturability of many bacterial strains, culture plate methods cannot be considered to be a gold standard any longer, although they are still of considerable relevance in and of themselves. Fluorescence staining methods as well as modern microscopic techniques such as AFM offer the opportunity to obtain completely new insights into the world of micro-organisms as well as their extracellular matrix (Dufrene, 2008). These still progressing techniques have not been fully utilized to date. Ultrastructure, viability and the metabolism of bacteria are quite variable. The same is true for the colonized substrates. In general, a combination of several methods is to be recommended when investigating adherent micro-organisms as the different methods yield distinctly different valuable information about these different aspects (Hannig et al., 2007b). Furthermore, the respective substrate should also be considered when selecting an appropriate method (Hannig \& Hannig, 2009).

\section{References}

Aas, J. A., Paster, B. J., Stokes, L. N., Olsen, I. \& Dewhirst, F. E. (2005). Defining the normal bacterial flora of the oral cavity. J Clin Microbiol 43, 5721-5732.

Al-Ahmad, A., Wunder, A., Auschill, T. M., Follo, M., Braun, G., Hellwig, E. \& Arweiler, N. B. (2007). The in vivo dynamics of Streptococcus spp., Actinomyces naeslundii, Fusobacterium nucleatum and Veillonella spp. in dental plaque biofilm as analysed by fivecolour multiplex fluorescence in situ hybridization. J Med Microbiol 56, 681-687.

Al-Ahmad, A., Wiedmann-Al-Ahmad, M., Auschill, T. M., Follo, M., Braun, G., Hellwig, E. \& Arweiler, N. B. (2008a). Effects of commonly used food preservatives on biofilm formation of Streptococcus mutans in vitro. Arch Oral Biol 53, 765-772.

Al-Ahmad, A., Wiedmann-Al-Ahmad, M., Carvalho, C., Lang, M., Follo, M., Braun, G., Wittmer, A., Mulhaupt, R. \& Hellwig, E. (2008b). Bacterial and Candida albicans adhesion on rapid prototypingproduced 3D-scaffolds manufactured as bone replacement materials. J Biomed Mater Res A 87, 933-943.

Al-Ahmad, A., Follo, M., Selzer, A. C., Hellwig, E., Hannig, M. \& Hannig, C. (2009a). Bacterial colonization of enamel in situ investigated using fluorescence in situ hybridization. $J$ Med Microbiol 58, 1359-1366.

Al-Ahmad, A., Roth, D., Wolkewitz, M., Wiedmann-Al-Ahmad, M., Follo, M., Ratka-Krüger, P., Deimling, D., Hellwig, E. \& Hannig, C. (2009b). Change in diet and oral hygiene over an eight week period: effects on oral health and oral biofilm. Clin Oral Investig (in press).

Amann, R. I. (1995). In situ identification of microorganisms by whole cell hybridization with rRNA-targeted nucleic acid probes. In Molecular Microbial Ecology Manual, 3.3.6., 1-15. Edited by A. D. L. Akkermans, J. D. van Elsas \& F. J. de Bruijin. Dordrecht: Kluwer.

Amann, R. I., Binder, B. J., Olson, R. J., Chisholm, S. W., Devereux, R. \& Stahl, D. A. (1990). Combination of $16 \mathrm{~S}$ rRNA-targeted oligonucleotide probes with flow cytometry for analyzing mixed microbial populations. Appl Environ Microbiol 56, 1919-1925.

Amann, R. I., Ludwig, W. \& Schleifer, K. H. (1995). Phylogenetic identification and in situ detection of individual microbial cells without cultivation. Microbiol Rev 59, 143-169.

Beletsky, I. P. \& Umansky, S. R. (1990). A new assay for cell death. J Immunol Methods 134, 201-205.

Bergmans, L., Moisiadis, P., Van Meerbeek, B., Quirynen, M. \& Lambrechts, P. (2005). Microscopic observation of bacteria: review highlighting the use of environmental SEM. Int Endod J 38, 775-788.

Bouchet-Marquis, C. \& Fakan, S. (2009). Cryoelectron microscopy of vitreous sections: a step further towards the native state. Methods Mol Biol 464, 425-439.

Boulos, L., Prevost, M., Barbeau, B., Coallier, J. \& Desjardins, R. (1999). LIVE/DEAD BacLight: application of a new rapid staining method for direct enumeration of viable and total bacteria in drinking water. J Microbiol Methods 37, 77-86.

Chavez de Paz, L. E. (2009). Image analysis software based on color segmentation for characterization of viability and physiological activity of biofilms. Appl Environ Microbiol 75, 1734-1739.

Daims, H., Lucker, S. \& Wagner, M. (2006). daime, a novel image analysis program for microbial ecology and biofilm research. Environ Microbiol 8, 200-213.

Dangl, J. L., Parks, D. R., Oi, V. T. \& Herzenberg, L. A. (1982). Rapid isolation of cloned isotype switch variants using fluorescence activated cell sorting. Cytometry 2, 395-401.

Decker, E. M. (2001). The ability of direct fluorescence-based, twocolour assays to detect different physiological states of oral streptococci. Lett Appl Microbiol 33, 188-192.

Dige, I., Nilsson, H., Kilian, M. \& Nyvad, B. (2007). In situ identification of streptococci and other bacteria in initial dental biofilm by confocal laser scanning microscopy and fluorescence in situ hybridization. Eur J Oral Sci 115, 459-467.

Donlan, R. M. \& Costerton, J. W. (2002). Biofilms: survival mechanisms of clinically relevant microorganisms. Clin Microbiol Rev 15, 167-193.

Dufrene, Y. F. (2008). Towards nanomicrobiology using atomic force microscopy. Nat Rev Microbiol 6, 674-680.

Glazer, A. N., Peck, K. \& Mathies, R. A. (1990). A stable doublestranded DNA-ethidium homodimer complex: application to 
picogram fluorescence detection of DNA in agarose gels. Proc Natl Acad Sci U S A 87, 3851-3855.

Gusberti, F. A., Finger, M. \& Lang, N. P. (1985). Scanning electron microscope study of 48 -hour plaque on different bridge pontics designs. Schweiz Monatsschr Zahnmed 95, 539-549.

Hannig, M. (1999). Transmission electron microscopy of early plaque formation on dental materials in vivo. Eur J Oral Sci 107, 55-64.

Hannig, M. \& Balz, M. (1999). Influence of in vivo formed salivary pellicle on enamel erosion. Caries Res 33, 372-379.

Hannig, C. \& Hannig, M. (2009). The oral cavity - a key system to understand substratum-dependent bioadhesion on solid surfaces in man. Clin Oral Investig 13, 123-139.

Hannig, C., Huber, K., Lambrichts, I., Graser, J., D’Haen, J. \& Hannig, M. (2007a). Detection of salivary alpha-amylase and lysozyme exposed on the pellicle formed in situ on different materials. J Biomed Mater Res A 83, 98-103.

Hannig, C., Hannig, M., Rehmer, O., Braun, G., Hellwig, E. \& AlAhmad, A. (2007b). Fluorescence microscopic visualization and quantification of initial bacterial colonization on enamel in situ. Arch Oral Biol 52, 1048-1056.

Hannig, C., Ruggeri, A., Al-Khayer, B., Schmitz, P., Spitzmüller, B., Deimling, D., Huber, K., Hoth-Hannig, W., Bowen, W. H. \& Hannig, M. (2008). Electron microscopic detection and activity of glucosyltransferase B, C, and D in the in situ formed pellicle. Arch Oral Biol 53, 1003-1010.

Hannig, C., Sorg, J., Spitzmüller, B., Hannig, M. \& Al-Ahmad, A. (2009). Polyphenolic beverages reduce initial bacterial adherence to enamel in situ. J Dent 37, 560-566.

Heydorn, A., Nielsen, A. T., Hentzer, M., Sternberg, C., Givskov, M., Ersboll, B. K. \& Molin, S. (2000). Quantification of biofilm structures by the novel computer program COMSTAT. Microbiology 146, 2395-2407.

Korber, D. R., Lawrence, J. R., Hendry, M. J. \& Caldwell, D. (1992). Programs for determining statistically representative areas of microbial biofilms. Binary 4, 204-210.

Korber, D. R., Lawrence, J. R., Hendry, M. J. \& Caldwell, D. E. (1993). Analysis of spatial variability within Mot + and Mot- Pseudomonas fluorescens biofilms using representative elements. Biofouling 7, 339-358.

Kristich, C. J., Li, Y. H., Cvitkovitch, D. G. \& Dunny, G. M. (2004). Espindependent biofilm formation by Enterococcus faecalis. J Bacteriol 186, 154-163.

Leeder, J. S., Dosch, H. M., Harper, P. A., Lam, P. \& Spielberg, S. P. (1989). Fluorescence-based viability assay for studies of reactive drug intermediates. Anal Biochem 177, 364-372.

Lloyd, D. \& Hayes, A. J. (1995). Vigour, vitality and viability of microorganisms. FEMS Microbiol Lett 133, 1-7.

Lopez-Amoros, R., Comas, J. \& Vives-Rego, J. (1995). Flow cytometric assessment of Escherichia coli and Salmonella typhimurium starvation-survival in seawater using rhodamine 123, propidium iodide, and oxonol. Appl Environ Microbiol 61, 2521-2526.

Marsh, P. D. (1993). Antimicrobial strategies in the prevention of dental caries. Caries Res 27 (Suppl. 1), s72-s76.

Marsh, P. D. \& Bradshaw, D. J. (1995). Dental plaque as a biofilm. $J$ Ind Microbiol 15, 169-175.

Marsh, P. \& Martin, M. (1999). Oral Microbiology. Oxford: Wright.

Mason, C. A., Hamer, G. \& Bryers, J. D. (1986). The death and lysis of microorganisms in environmental processes. FEMS Microbiol Lett 39, 373-401.

Møller, S., Korber, D. R., Wolfaardt, G. M., Molin, S. \& Caldwell, D. E. (1997). Impact of nutrient composition on a degradative biofilm community. Appl Environ Microbiol 63, 2432-2438.
Mueller, L. N., de Brouwer, J. F., Almeida, J. S., Stal, L. J. \& Xavier, J. B. (2006). Analysis of a marine phototrophic biofilm by confocal laser scanning microscopy using the new image quantification software PHLIP. BMC Ecol 6, 1.

Netuschil, L., Reich, E. \& Brecx, M. (1989). Direct measurement of the bactericidal effect of chlorhexidine on human dental plaque. J Clin Periodontol 16, 484-488.

Netuschil, L., Weiger, R., Preisler, R. \& Brecx, M. (1995). Plaque bacteria counts and vitality during chlorhexidine, meridol and listerine mouthrinses. Eur J Oral Sci 103, 355-361.

Nielsen, A. T., Tolker-Nielsen, T., Barken, K. B. \& Molin, S. (2000). Role of commensal relationships on the spatial structure of a surfaceattached microbial consortium. Environ Microbiol 2, 59-68.

Nyvad, B. \& Kilian, M. (1987). Microbiology of the early colonization of human enamel and root surfaces in vivo. Scand J Dent Res 95, 369380.

Paster, B. J., Bartoszyk, I. \& Dewhirst, F. E. (1998). Identification of oral streptococci using PCR-based, reverse-capture, checkerboard hybridization. Methods Cell Sci 20, 223-231.

Peeters, E., Nelis, H. J. \& Coenye, T. (2008). Comparison of multiple methods for quantification of microbial biofilms grown in microtiter plates. J Microbiol Methods 72, 157-165.

Roth, B. L., Poot, M., Yue, S. T. \& Millard, P. J. (1997). Bacterial viability and antibiotic susceptibility testing with SYTOX green nucleic acid stain. Appl Environ Microbiol 63, 2421-2431.

Sauer, K., Thatcher, E., Northey, R. \& Gutierrez, A. A. (2009). Neutral super-oxidised solutions are effective in killing $P$. aeruginosa biofilms. Biofouling 25, 45-54.

Schaber, J. A., Hammond, A., Carty, N. L., Williams, S. C., ColmerHamood, J. A., Burrowes, B. H., Dhevan, V., Griswold, J. A. \& Hamood, A. N. (2007). Diversity of biofilms produced by quorumsensing-deficient clinical isolates of Pseudomonas aeruginosa. J Med Microbiol 56, 738-748.

Schwartz, T., Hoffmann, S. \& Obst, U. (2003). Formation of natural biofilms during chlorine dioxide and u.v. disinfection in a public drinking water distribution system. J Appl Microbiol 95, 591-601.

Stepanovic, S., Vukovic, D., Dakic, I., Savic, B. \& Svabic-Vlahovic, M. (2000). A modified microtiter-plate test for quantification of staphylococcal biofilm formation. J Microbiol Methods 40, 175-179.

Thurnheer, T., Gmur, R., Giertsen, E. \& Guggenheim, B. (2001). Automated fluorescent in situ hybridization for the specific detection and quantification of oral streptococci in dental plaque. J Microbiol Methods 44, 39-47.

Vitkov, L., Hermann, A., Krautgartner, W. D., Herrmann, M., Fuchs, K., Klappacher, M. \& Hannig, M. (2005). Chlorhexidine-induced ultrastructural alterations in oral biofilm. Microsc Res Tech $\mathbf{6 8}$, 85-89.

Weiger, R., Decker, E. M., Krastl, G. \& Brecx, M. (1999). Deposition and retention of vital and dead Streptococcus sanguinis cells on glass surfaces in a flow-chamber system. Arch Oral Biol 44, 621-628.

Xavier, J. B., Schnell, A., Wuertz, S., Palmer, R., White, D. C. \& Almeida, J. S. (2001). Objective threshold selection procedure (OTS) for segmentation of scanning laser confocal microscope images. J Microbiol Methods 47, 169-180.

Yang, X., Beyenal, H., Harkin, G. \& Lewandowski, Z. (2000). Quantifying biofilm structure using image analysis. J Microbiol Methods 39, 109-119.

Yang, X., Beyenal, H., Harkin, G. \& Lewandowski, Z. (2001). Evaluation of biofilm image thresholding methods. Water Res 35, 1149-1158. 